\title{
Efficient Evaluation of Biodiversity Concerns in Protected Areas
}

\author{
Sam Ferreira, ${ }^{1,2}$ Mahlomola Daemane, ${ }^{3}$ Andrew Deacon, ${ }^{1}$ \\ Hendrik Sithole, ${ }^{3}$ and Hugo Bezuidenhout ${ }^{3,4}$ \\ ${ }^{1}$ Savanna and Arid Research Unit, Conservation Services, South African National Parks, Private Bag X402, Skukuza 1350, South Africa \\ ${ }^{2}$ School of Biological \& Conservation Sciences, University of KwaZulu-Natal, P/Bag X01, Scottsville, \\ Pietermaritzburg 3209, South Africa \\ ${ }^{3}$ Savanna and Arid Research Unit, Conservation Services, South African National Parks, P.O. Box 110040, Hadison Park, \\ Kimberley, 8306, South Africa \\ ${ }^{4}$ Applied Behavioural Ecology and Ecosystem Research Unit, UNISA, Private Bag X6, Florida 1717, South Africa
}

Correspondence should be addressed to Hugo Bezuidenhout; hugo.bezuidenhout@sanparks.org

Received 4 March 2013; Revised 28 June 2013; Accepted 17 July 2013

Academic Editor: Pere Pons

Copyright (C) 2013 Sam Ferreira et al. This is an open access article distributed under the Creative Commons Attribution License, which permits unrestricted use, distribution, and reproduction in any medium, provided the original work is properly cited.

\begin{abstract}
Monitoring is a vital component of keeping protected areas in desired states. Lack of robust designs, however, impedes efficient monitoring. We ask two questions-how does effort at a specific site as well as number of sites in a plant community influence richness, abundance, and diversity indicators. Large mammal herbivory biodiversity influences are a key concern for managers of Mokala National Park. We anticipated that changes in biodiversity indicators (vegetation, ants, and birds) associate with herbivore intensity of use of landscapes. We identified flat deep sandy plains and undulating shallow rocky hills as focal landscapes. Our focus was on finding optimized effort at survey sites as well as the number of sites. Monitoring to evaluate change in diversity and abundance needs far less effort than evaluating change in richness. Furthermore, given the variance at the landscape level, monitoring of species abundance and diversity allows easier detection with less effort and at shorter intervals between surveys than that required for richness. Even though a mechanisms-based approach directs monitoring, conservationists need to evaluate feasibility. In our case, measurement of richness is unlikely to detect herbivore effects. In general though, we have illustrated that focused monitoring designs can robustly evaluate conservation objectives.
\end{abstract}

\section{Introduction}

Ecological monitoring is a key component of adaptive management [1-3], an approach commonly used in resource management when faced with uncertainty [4]. In theory, adaptive management requires managers to have information or opinions on how a specific ecosystem is functioning. The information or opinion of ecosystem functioning predicts how a system should respond. Managers measure these predictions robustly and adapt management actions accordingly if needed [5].

Monitoring designs, however, are often haphazard at best [6]. Reasons include ill-defined objectives or linkages to higher level objectives such as that of park management plans, uncertainties of ecological indices, and what to measure to evaluate a specific objective [7]. Consolidated planning that focuses on defining mechanisms (i.e., the way in which a factor has biological effects, and what modulators adjust or regulate a mechanism) of how threats may impose on managers achieving objectives (i.e., the outcome they seek to achieve) [8] may address many of these shortcomings. Even if these shortcomings have been accounted for, managers often face uncertainties in how to measure responses robustly [7].

Such challenges carry trade-offs that place resource managers at risk of not achieving objectives. For instance, they can respond quickly if a negative trend in the abundance of a threatened species is detected easily. However, the precision of abundance estimates of rare species restricts easy detection and requires lengthy time series or longer intervals between surveys [9]. By the time a trend is detected, extensive change has already happened. This reality places particular strain on the traditional use of thresholds of potential concerns 
(TPCs) which seek to predict change and respond before actual change occurs [10].

In addition, modern conservation practices capture sociological, economic and ecological factors that introduce complexity [11, 12]. This complexity forms a key focus of objectives defined within management plans of protected areas [13]. Even so, maintaining all facets and fluxes of biodiversity is a key focus for managing authorities (e.g., [8]). Uncertainty associated with achieving conservation objectives will thus carry societal and political risks [1417]. It may even lead to consequences detrimental to human society at large. For instance, despite water quality indicators in the Olifants River of Kruger National Park being the healthiest in 2009, there was a spate of crocodile deaths in the park [18]. The event can be attributed to accumulating deterioration of South African river ecosystems [19-22]. In this case a once off condition of indicators may not be reflective of the integrity of biodiversity per se. The deaths of an apex predator are indicative of a degraded ecosystem on which many people depend [18]. Furthermore, making haphazard causal inference when complex processes mediate ecological change [23] inherently carries uncertainty about mechanisms of threats. This may result in actions that have no meaningful contribution to dealing with the problem [23].

The robust design of monitoring, once objectives have been defined, is thus a key step in completing the adaptive management loop adopted by many conservation agencies $[24,25]$. We used a case study in the Mokala National Park (Mokala) to illustrate the design of a monitoring programme. Mokala is a relatively small park with several large mammal species, such as buffalo (Syncerus caffer), black (Diceros bicornis bicornis), and white rhino (Ceratotherium simum simum). As part of the biodiversity objectives of Mokala, the herbivory influence on biodiversity was raised as a key concern for park managers [8]. The effect of herbivory by large mammals primarily originates from their intensity of use of landscapes [8]. Responses to temporal and spatial variation in resource availability and quality, however, are restricted in small fenced reserves [26] leading to intensified use of landscapes. Such intensified use of landscapes by large mammals may challenge managers in achieving biodiversity related objectives specified for a protected area.

Changes in species and community composition as well as vegetation structure are indicators of changing abiotic (e.g., soil, hydrology, and nutrient dynamics) [27] and biotic conditions (e.g., invasive plants, animals, insects, emerging diseases) [28]. Because plant community parameters such as richness, abundance, and diversity are repeatable over time, analysis of trends can generate a predictive model for determining the future outcomes of ecosystems [29]. Herbivores affect plant communities through both abiotic and biotic pathways [30]. Diversity and abundance measures are thus likely to reflect mechanisms of the effect of herbivory on biodiversity. We thus anticipated that changes in ecological indicators (vegetation, ants, and birds) should be associated with herbivore intensity of use of landscapes. For this purpose our monitoring programme is thus directed at detecting trends.
Trend detection of any variable is a trade-off between several factors but is largely influenced by precision [31, 32] of estimates of the variable [9]. Here we focus on finding ways to optimize precision of estimates of variables for a specific plant community through optimized effort at survey sites as well as the number of sites. We then use Gerrodette's [9] inequality to evaluate trade-offs between length of a time series of estimates, intervals between surveys, time to detect change, and total change by the time change is detected to propose optimal monitoring designs. Our results allow us to make suggestions for monitoring designs in general and for Mokala specifically. We are cautious though as case studies may not be sufficient to generalize the results and the proposed monitoring scheme should be tested more widely.

\section{Material and Methods}

2.1. Study Area. Mokala is situated approximately $80 \mathrm{~km}$ south-southwest of Kimberley in South Africa (Figure 1) with landscapes varying from hills to large open plains. Drainage lines out of these hills run into the plains where there are pans, as well as into the Riet River.

The rainfall, mainly during summer, is erratic ranging from $300 \mathrm{~mm}$ to $700 \mathrm{~mm}$ per year with average just over $400 \mathrm{~mm}$ per annum. The temperature ranges from $-4^{\circ} \mathrm{C}$ during winter (coldest months June-July) to $44^{\circ} \mathrm{C}$ during summer (warmest months December-January). Frost occurs from April to September [33].

Three vegetation types occur in the park. The Kimberley Thornveld (Svk4) and Vaalbos Rocky Shrubland (Svk5) represent the Savanna Biome, whereas the Northern Upper Karoo (NKu 3) represents the Nama Karoo Biome [34]. We recognized six major plant communities including: (1) Acacia erioloba-Acacia tortilis open woodland; (2) Rhigozum obovatum-Acacia mellifera open shrubland; (3) Acacia mellifera-Acacia tortilis open woodland; (4) Acacia melliferaAcacia erioloba open to closed woodland; (5) Schmidtia pappophroides-Acacia erioloba open grassland; (6) Cynodon dactylon-Ziziphus mucronata open woodland [35].

Mokala National Park has a specious large mammal presence with 17 antelope herbivores and two rhinoceros species present. The antelopes range from the small steenbok (Raphicerus campestris) to the large eland (Taurotragus oryx). At least two species are extralimital (impala Aepyceros melampus and nyala Tragelaphus angasii). The larger antelopes and rhinos are most likely drivers of herbivory effects on vegetation and associated biodiversity. Note that Mokala is fenced with numerous boreholes providing water throughout the park.

2.2. Sampling Design. We identified two landscapes based on geology, soil, and vegetation. These included relatively flat deep sandy (Aeolian) plains and the undulating shallow rocky (Dolerite) hills. Our focus was on the two most diverse plant communities within these landscapes namely the Acacia mellifera-Acacia erioloba open to closed woodland (Aerepresentative of sandy plains) and the Rhigozum obovatum-Acacia mellifera open Shrubland (Ro-representative of rocky hills). 


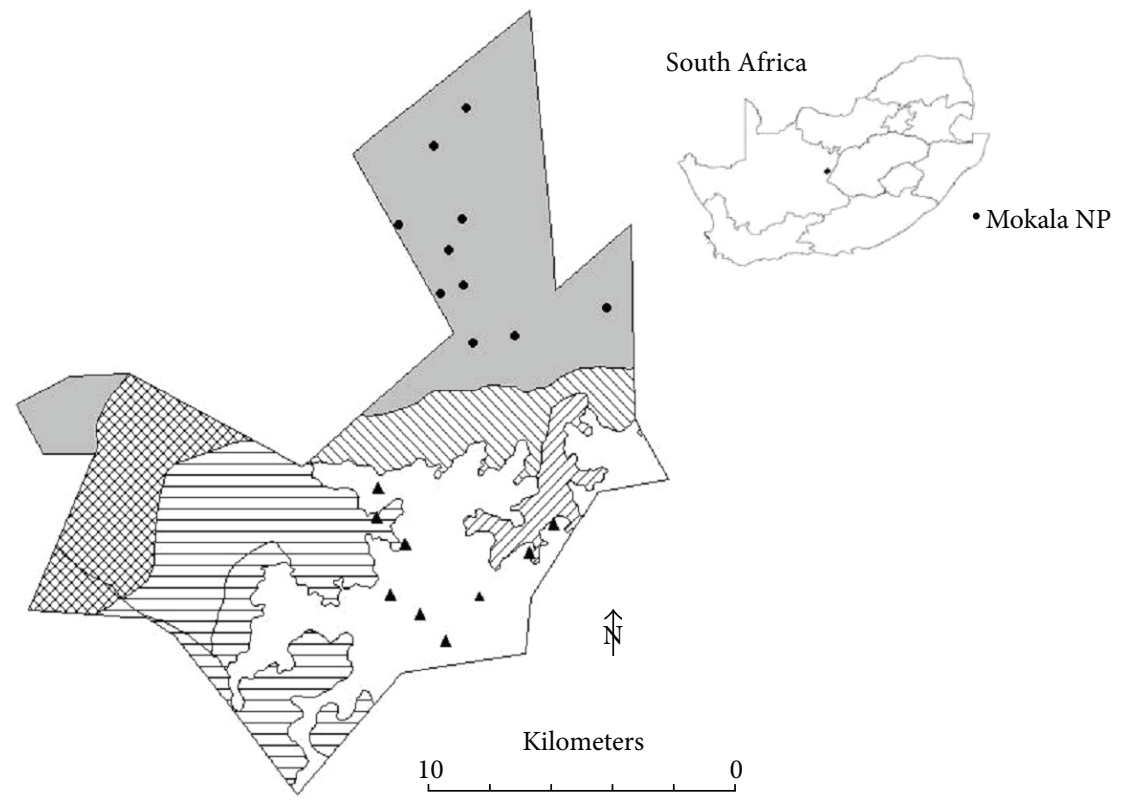

$\begin{array}{ll}\text { Plant communities } & \square \text { Mokala National Park } \\ \square \text { Acacia erioloba-Acacia tortilis open woodland } & \text { Sampling plots } \\ \square \text { Acacia mellifera-Acacia erioloba open to closed woodland } & \bullet \text { Ae } \\ \square \text { Acacia mellifera-Acacia tortilis open woodland } & \text { Ro } \\ \square \text { Cynodon dactylon-Ziziphus mucronata open shrubland } & \\ \square \text { Rhigozum obovatum-Acacia mellifera open shrubland } & \\ \text { Schmidtia pappophoroides-Acacia erioloba grassland } & \end{array}$

FIGURE 1: A locality map and map of the major plant communities of the Mokala National Park. We also indicate where each sample site was within the two focal plant communities representing sandy plains (Acacia mellifera-Acacia erioloba open to closed woodland Ae) and rocky hills (Rhigozum obovatum-Acacia mellifera open shrubland Ro).

For this study we chose plant, ant, and bird communities as response variables that we wish to detect trends for. We also evaluated requirements to detect trends in mammal dung densities [36], an indicator of intensity of use. Vegetation is key to large mammals (e.g., [10]) and also likely to have effects on other species and assemblages. Ants provide good information related to monitoring ecosystem conditions by responding to anthropogenic activities, invasive organisms and land management actions [37-40]. Birds are an important component of many ecosystems, and counts of birds accurately reflect environmental changes [41]. A decline in species richness and diversity of birds, as determined by routine monitoring, may serve thus as an early warning of environmental degradation [42].

Within each of the focal plant communities we had a specific design at each sample site (rocky hills: $n=9$; sandy plains: $n=10$; see Figure 1). At each site we established a vegetation plot and overlaid an ant sampling plot. These plots formed the focal point of our sampling from which transects for bird and dung surveys were laid out. We applied transect surveys differently in the rocky hills and sandy plains plant communities due to logistical ease to walk transects. For the sandy plains vegetation we walked 4 transects of $250 \mathrm{~m}$ and two transects of $350 \mathrm{~m}$ in a butterfly pattern with

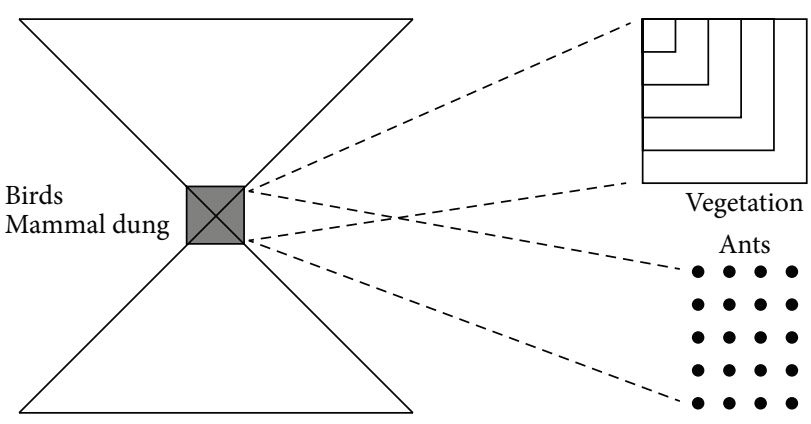

Figure 2: Sample design for surveys of vegetation, ants, birds and mammal dung applied to each sample site within each plant communities. Note the butterfly pattern of transects for bird and mammal dung surveys centering on plots for vegetation and ant surveys. Birds and mammals were recorded while walking these transects as described in the text.

the vegetation and ant plots in the centre of the transect pattern. In the rocky hills, transects were 4 of $150 \mathrm{~m}$ length and 2 of $210 \mathrm{~m}$ length in the same butterfly pattern (Figure 2).

Our conceptual approach ask two questions-how does effort at a specific site influence site-specific richness, abundance, and diversity measures and how does the number of 
sites in a plant community influence vegetation-specific richness, abundance, and diversity. To address the first question we increased vegetation plot size at a site as an index of effort (see Figure 2), while the number of trap days (i.e., one pitfall trap active for one day equates to one trap day) served as an index of effort for ant sampling. For bird and mammal dung surveys, the distance along transects served as indicators of effort. Number of sites sampled served as indicators of effort within a plant community.

\subsection{Data Collection}

Plant Communities. We used a species accumulation curve to help us determine the minimum plot size to sample vegetation [43]. For this purpose, we established an initial plot size of $1 \times 1 \mathrm{~m}$ at one selected sample site per plant community. We then progressively increased plot size to $11 \times 11 \mathrm{~m}$ in the sandy soil plant community and $9 \times 8 \mathrm{~m}$ in the rocky hills plant community. At each increment of increase we noted the number of new species found and added it to the total already found.

Plant sampling was undertaken in ten plots on sandy plains and nine in rocky hills plant communities. A plot size of $64 \mathrm{~m}^{2}(8 \times 8 \mathrm{~m})$ was used in all plant communities following our assessment through species accumulation curves [43]. Identification of plant species was done in each plot, and species names were according to Germishuizen and Meyer [44]. The cover abundance [45] of each species was visually estimated using the Braun-Blanquet cover abundance scale [43]. The average height and canopy cover for tree, shrub, and herbaceous strata were recorded. Determination of soil form and depth was done using a soil auger, and the percentage clay in the soil was also estimated [46]. Environmental data such as percentage of surface rockiness and bare soil patches was also recorded.

Ant Communities. We used a species accumulation curve to help us determine the minimum days we need to sample ants representative of each community. For this purpose, we divided day sampling frequency in three parts (namely, every day, after two days, and after three days). At each sampling frequency we noted species sampled.

A pitfall trap method [47] comprising twenty traps in a $5 \times$ 4 trapping configuration spaced $10 \mathrm{~m}$ apart was placed in each plot at sites within plant communities. We used $100 \mathrm{~mL}$ plastic cups as traps containing $50 \mathrm{~mL}$ of $50 \%$ propylene glycolwater solution as preservative solution to prevent water evaporation. The propylene-glycol solution has been reported to not significantly attract or repel ants [48]. We set traps for different days (from one sampling day to three days) to determine the sampling days required to adequately sample ant species present in each plant community (Table 1). Ants were identified to genus level using Bolton [49] and further to species level using external morphological characters.

Bird Communities. Our method made use of fixed routes along transects placed at each study site [41] and recorded birds seen and heard up to $30 \mathrm{~m}$ on either side of the route. Transects were partitioned into $50 \mathrm{~m}$ intervals, and
TABLE 1: Summary of ant specimen collection at sample sites within plant communities in Mokala National Park.

\begin{tabular}{lcccc}
\hline & & \multicolumn{3}{c}{ Sites where pitfalls were checked and } \\
& Sites set & Day 1 & Day 2 & Day 3 \\
\cline { 3 - 5 } & & Daymens collected & All \\
Sandy plains & 10 & $4,8,7,9,10$ & $4,5,6,7,8,9,10$ & All \\
Rocky hills & 8 & - & - & All \\
\hline
\end{tabular}

we recorded birds per distance interval. For birds seen, we also recorded habitat features within which we observed individuals (see Ryder [42]). Our surveys took place during the first three to four hours after first light as we anticipated bird activity to be optimal during this period. We restricted our surveys to relatively calm, sunny days.

Mammal Dung Densities. Dung transects at each sample site formed the key focus of our survey as an indicator of the use of plant communities by large mammals. Mokala contains several species, many of which "species" dung is hard to distinguish from each other with certainty. We thus noted herbivore dung in different size classes defined by bolus diameter (i.e., size classes included $0-5 \mathrm{~mm}, 6-10 \mathrm{~mm}, 11-15 \mathrm{~mm}$, 16-20 mm, 21-25 mm, 26-30 mm, 31-50 mm, and >50 mm). We recorded easily identifiable dung such as that of white rhino, black rhino, and buffalo droppings separately from the other herbivore droppings. We also noted the distance along the transect when droppings were encountered.

2.4. Data Analyses. Our assessment focused on three response variables-species richness (i.e., the number of species), abundance (i.e., the density of individuals of a given species in a plot or at a site), and diversity (i.e., a composite measure of the number of species, as well as their relative abundances) [50].

Site-Specific Effort. We used a generalized accumulation curve $\left(y=a x^{b}\right)$ to evaluate how species richness, abundance, and diversity changes with an increase in survey efforts. For richness we estimated the cumulative number of species per increasing unit of effort (i.e., plants: $1 \mathrm{~m}^{2}$, ants: 1 pitfall trap day; birds: 1 distance unit equal to $50 \mathrm{~m}$; and mammals: 1 distance unit equal to $50 \mathrm{~m}$ ). We defined desirable effort when the number of species increased by less than $10 \%$ per unit increase in effort.

The vegetation data recorded on increasing plot sizes did not allow us to estimate abundance for this part of the study. For ants and birds we used the total number of specimens collected per pitfall and total number of individuals observed per distance unit, respectively, as indices of abundance. Mammal abundance was defined as the number of incidences of droppings per distance unit. For each level of effort we calculated abundance to generate a time series of densities against increasing survey effort. We then calculated the coefficient of variance $(\mathrm{CV})$ in abundance indices at each increasing measure of effort. We used the same accumulation curve as before and defined the desirable effort to estimate 
abundance when CV changed by less than $10 \%$ with increase in effort.

We could only calculate the Shannon-Wiener index of diversity $\left(H=-\sum p \log p\right.$, where $p$ is the proportional abundance of each species [51]) for ants and bird assemblages as part of the study. We calculated diversity at each increasing survey effort and used the accumulation curve to define the desirable effort when diversity changed by less than $10 \%$ with increase in effort.

Plant Community Specific Effort. For this part of the analyses we estimated richness, abundance and diversity when we increased the number of sites from 1 to 10 in the sandy plains plant community and 1 to 9 in the rocky hills community. Using the same accumulation curve as for site-specific analyses, we estimated the number of sites required within a plant community defined when richness, CV in abundance, and diversity changed by less than $10 \%$ with increase in number of sites.

Survey Trade-Offs. We defined survey requirements if conservationists seek to detect $5 \%$ annual change, in our case $5 \%$ increase in species richness, abundance, and diversity. We used Gerrodette's [9] inequality defined as

$$
\begin{aligned}
& {[\ln (1+r)]^{2} n(n-1)(n+1)} \\
& \quad \geq 12\left(z_{\alpha / 2}+z_{\beta}\right)^{2}\left\{\frac{1}{n} \sum_{1}^{n} \ln \left[\frac{\mathrm{cv}^{2}}{(1+r)^{i-1}}+1\right]\right\},
\end{aligned}
$$

where $r$ is the exponential growth rate set at 0.05 (i.e., $5 \%$ per annum), $n$ is the number of surveys, $z_{\alpha / 2}$ and $z_{\beta}$ are the inverse of the standard normal distribution at $\alpha$ and $\beta, i$ is the interval between surveys in years, and $\mathrm{cv}$ is the coefficient of variance. Values of $\alpha$ reflect minimizing making a type I error (concluding that there is a trend when in fact there is none), while $1-\beta$ reflect minimizing making a type II error (concluding that there is no trend when in fact there is). We varied survey intervals to define trade-offs between intervals, number of surveys, and time to detect trends.

\section{Results}

3.1. Site-Specific Effort. Variables typically conformed to predicted accumulation curves (Figure 3 ). We could define survey efforts where species richness, CV in abundance, and diversity changed by less than $10 \%$. We summarize the patterns for plant, ant, and bird communities across sites as an indicator of the average optimal required effort.

Plant Communities. Minimum plot size to determine species richness in sandy plains is smaller than that for the rocky hills (Table 2). Our survey standardized plot size to $8 \times 8 \mathrm{~m}$, larger than that required for optimal definition of species richness.

Ant Communities. Surveyors will require 55 to 65 trap days irrespective of plant community to determine ant species richness at a sample site. Substantially less effort ( 6 to 8 pitfall days) is required for ant abundance and diversity in both sandy plains and rocky hills (Table 2).
Bird Communities. Evaluating bird diversity requires the least effort (111 $\mathrm{m}$ to $256 \mathrm{~m}$ ), while that needed for richness was the highest (1318 $\mathrm{m}$ to $2326 \mathrm{~m}$ ) irrespective of plant community (Table 2).

Mammal Dung Densities. Coefficient of variance (CV) for mammal dung densities stabilized at relatively shorter distances in rocky hills compared to sandy plains (Table 2). In both cases the total length of transects surveyed during the present study exceeded the optimal requirement.

\subsection{Vegetation-Specific Effort}

Plant Communities. The optimal number of sample sites required to detect vegetation richness is high for both sandy plains and rocky hills (Table 3). Substantially fewer sampling sites are required for detection of vegetation abundance in both the sandy plains and rocky hills. Only three sampling sites are required to define vegetation diversity in both the sandy plains and rocky hills.

Ant Communities. Substantially more sample sites than actually surveyed are needed to define species richness in sandy plains as well as in rocky hills (Table 3 ). For abundance and diversity, surveyors need to use far fewer sample sites (2 to 3 ) sites.

Bird Communities. Diversity will be the easiest aspect to define requiring 7-12 sites per plant community (Table 3). On the other hand, significantly more sites are needed to define species richness in both plant communities. Definition of abundance required between 19 to 29 sites.

Mammal Dung Densities. Defining dung densities with consistent CVs within a plant community required 10 sample sites (Table 3). Only 9 sites were sampled in the rocky hills.

\subsection{Survey Trade-Offs}

Plant Communities. In order to detect 5\% change in vegetation richness and abundance for both plant communities, the intervals between surveys, total number of surveys, and the number of years required are 5, 2, and 5, respectively, for $28 \%$ total change. This indicates that if the survey interval is every year, more effort will be required $(n=6)$ to detect the same total change $(28 \%)$ as in 5-year interval, except that the effort in the latter is less $(n=2)$. The same interval is also required to detect $16 \%$ total change in species diversity. The same effort is also required in the rocky hills to detect total change of $28 \%$ in both species richness and abundance and 16\% change for diversity.

Ant Communities. Defining abundance requires annual surveys in both plant communities, but surveyors will only detect $5 \%$ annual change in 12 to 13 years (Table 4 ). By that time, total change in abundance would range from 80 to $90 \%$. For richness and diversity, surveyors can obtain reliable estimates by surveying sites every 4-5 years and will detect $5 \%$ annual change in 5- to 8-year time. 


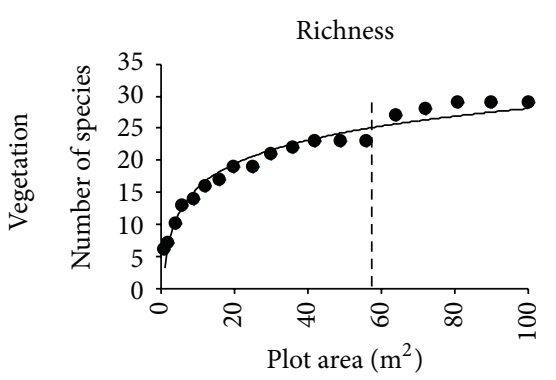

Abundance

Diversity
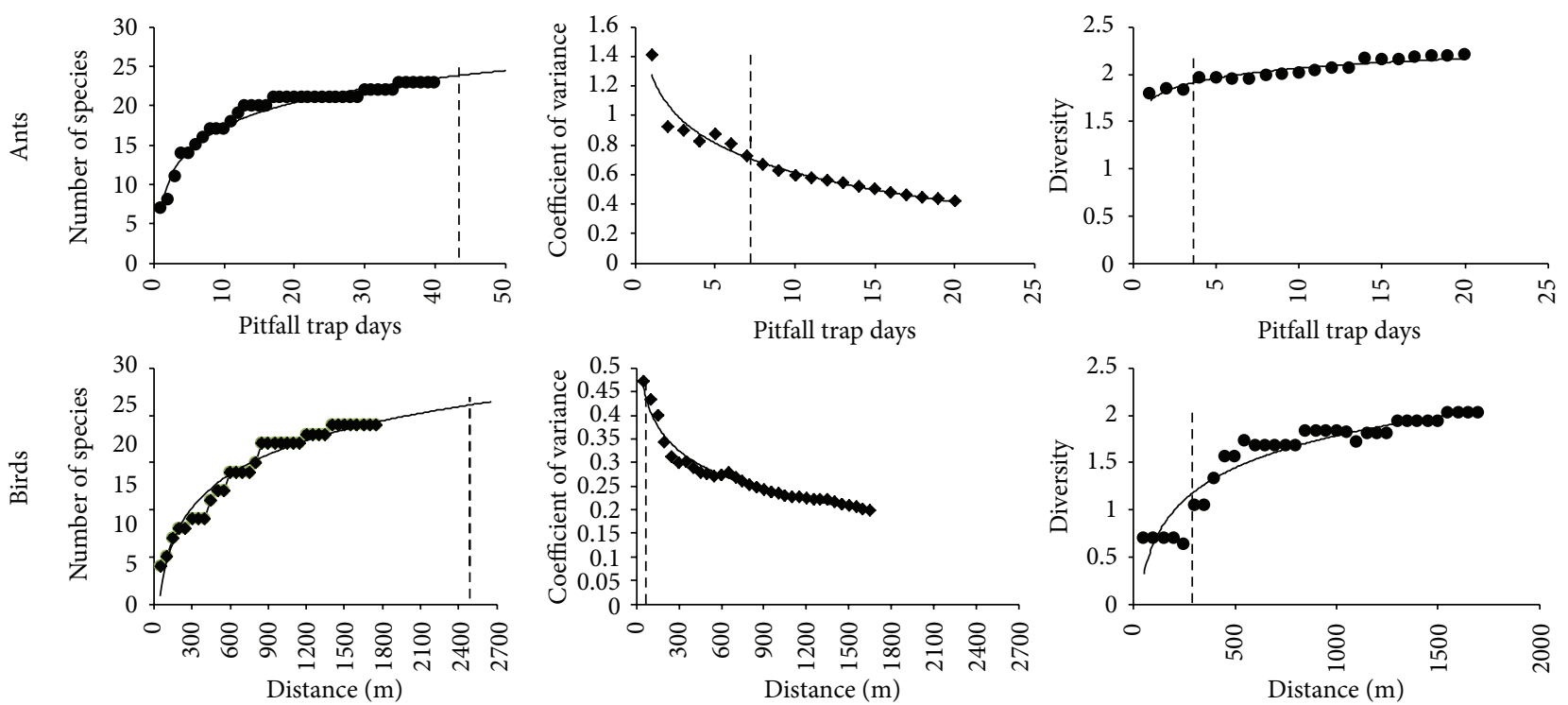

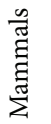

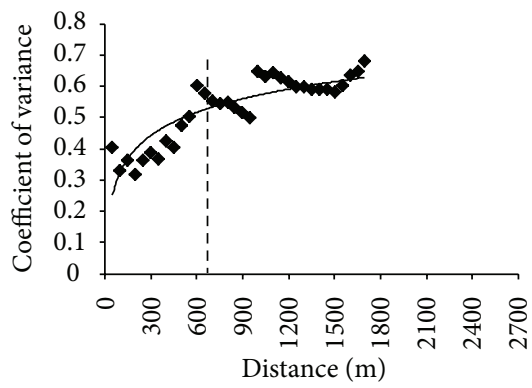

FIGURE 3: Examples of changes in richness, coefficient of variance in abundance, and diversity in vegetation, ant, and bird assemblages as well as mammal dung estimates. The vertical broken lines indicate the effort at which a variable is changing less than $10 \%$ with increase in effort. The $x$-axes reflect various measures of effort for the different taxa.

Bird Communities. The optimal survey trade-off consistently predicted that this group should be surveyed annually, irrespective of the variable, and it will take between 7 to 11 years to detect a $5 \%$ annual change (Table 4 ).

Mammal Dung Densities. Coefficient of variance in dung densities recorded on sandy plains predicted annual survey requirements for 8 years to detect an annual change of $5 \%$. In contrast, surveyors only need to survey dung densities every five years on rocky hills and will detect $5 \%$ annual change after three surveys in 10-year time (Table 4).

\section{Discussion}

The application of adaptive management to ecosystem management imposes a strong requirement of learning-by-doing
[5]. This reality restricts the traditional monitoring approaches of tracking patterns of subjectively defined variables [6]. In such cases, undesirable changes are typically followed by some or other research project, but rarely by timely interventions. Adaptive management approaches seek to overcome such risks. Optimal monitoring programmes in this context may thus carry large informative value for resource managers [52-55]. This is aided by welldefined conservation objectives [7], the unpacking of the mechanisms of concerns, or in what way threats impose on persistence of biodiversity values [13]. Adaptive management implementation follows that made predictions on how a system should respond to management actions [5]. We argue that the final loop requires designing a monitoring programme aimed at evaluating predictions which invariably requires detecting directional change over time. 
TABLE 2: Summary of site-specific survey requirements to define richness, abundance, and diversity for plant, ant, and bird communities in Mokala National Park. We also illustrate the requirements to define dung abundances of large mammals.

(a) Sandy plains

\begin{tabular}{lcccccc}
\hline & \multicolumn{2}{c}{ Richness } & \multicolumn{2}{c}{ Abundance } & \multicolumn{2}{c}{ Diversity } \\
& $\bar{x} \mp \operatorname{stdev}[\bar{x}]$ & $\operatorname{Min}[x]$ to $\operatorname{Max}[x]$ & $\bar{x} \mp \operatorname{stdev}[\bar{x}]$ & $\operatorname{Min}[x]$ to $\operatorname{Max}[x]$ & $\bar{x} \mp \operatorname{stdev}[\bar{x}]$ & $\operatorname{Min}[x]$ to $\operatorname{Max}[x]$ \\
\hline Plants $\left(\mathrm{m}^{2}\right)$ & $52 \pm 9$ & $46-59$ & - & - & - & - \\
Ants (pitfall days) & $63 \pm 22$ & $40-106$ & $6 \pm 5$ & $1-17$ & $8 \pm 6$ & $1-20$ \\
Birds (m) & $2326 \pm 864$ & $1060-4110$ & $96 \pm 122$ & $34-442$ & $256 \pm 147$ & $29-426$ \\
Mammals (m) & - & - & $562 \pm 470$ & $45-1568$ & - & - \\
\hline
\end{tabular}

(b) Rocky hills

\begin{tabular}{lcccccc}
\hline & \multicolumn{2}{c}{ Richness } & \multicolumn{2}{c}{ Abundance } & \multicolumn{2}{c}{ Diversity } \\
& $\bar{x} \mp \operatorname{stdev}[\bar{x}]$ & $\operatorname{Min}[x]$ to $\operatorname{Max}[x]$ & $\bar{x} \mp \operatorname{stdev}[\bar{x}]$ & $\operatorname{Min}[x]$ to $\operatorname{Max}[x]$ & $\bar{x} \mp \operatorname{stdev}[\bar{x}]$ & $\operatorname{Min}[x]$ to $\operatorname{Max}[x]$ \\
\hline Plants $\left(\mathrm{m}^{2}\right)$ & 57 & - & - & - & - & - \\
Ants (pitfall days) & $56 \pm 17$ & $37-86$ & $6 \pm 7$ & $1-22$ & $6 \pm 3$ & $3-12$ \\
Birds (m) & $1318 \pm 546$ & $463-1957$ & $383 \pm 116$ & $214-545$ & $111 \pm 66$ & -245 \\
Mammals (m) & - & - & $441 \pm 242$ & $140-806$ & - & - \\
\hline
\end{tabular}

TABLE 3: Summary of optimal vegetation-specific number of sample sites to define richness, abundance, and diversity of plant, ants, and birds within a vegetation community. We also illustrate the requirements to define dung abundances of large mammals.

\begin{tabular}{|c|c|c|c|c|c|c|}
\hline & \multicolumn{2}{|c|}{ Richness } & \multicolumn{2}{|c|}{ Abundance } & \multicolumn{2}{|c|}{ Diversity } \\
\hline & Sandy plains & Rocky hills & Sandy plains & Rocky hills & Sandy plains & Rocky hills \\
\hline Plants & 183 & 206 & 2 & 8 & 3 & 3 \\
\hline Ants & 80 & 67 & 2 & 2 & 2 & 3 \\
\hline Birds & 166 & 106 & 29 & 19 & 12 & 7 \\
\hline Mammals & - & - & 10 & 10 & - & - \\
\hline
\end{tabular}

Our results suggest that sample size or scale [56], monitoring frequency [9], and variables to measure are largely influenced by precision, which affects the ability to detect change. We could stabilize estimates of variables (species richness, abundance, and diversity) at a sample site level with the efforts in our study. For species richness though, excessive number of plots and pitfall trap days or long walking transects are needed to stabilize species richness measures at a landscape scale. Modeling landscape variation in species richness was subject to statistical constraints when richness estimates are restricted to few sampling sites [57]. The interaction between scale and variables is not supported for measures of abundance and diversity. Detection of change in species abundance and diversity in plants, birds, and ants as well as abundance in mammals requires less effort and shorter survey intervals than those required for species richness.

Observers do face some challenges because the requirements for different taxa are not similar. At site level we could easily measure all variables. At the landscape level, however, birds required much larger effort to stabilize abundance and diversity measures than what plant species and ants did. A number of factors associated with specific habitat features determine distribution and abundance of birds [42]. It is, however, the temporary nature of presence-absence of individuals through short-term movements [58] that constrains robust estimation of key variables for them. Observers require regular surveys for an extended period to detect trends in birds. This carry risks and costs that may not justify including birds in generalized monitoring designs. Bird communities, however, were identified as an important measure in evaluating whether management actions deal with herbivory concerns at Mokala [8]. The bird survey constraint can be overcome by considering the temporal nature of field observations of birds. Elsewhere, repeated measures of the same transect comprising a single sampling occasion overcame temporal bird activity constraints $[58,59]$. Optimal designs should then consider the level of repeated efforts needed to stabilize measures.

We recognize that biological diversity can be quantified in many different ways. In defining change over time, measures will differ from case to case depending on the concern raised and the mechanism of how that concern comes about [13]. We argue that, statistical properties and robustness imposed on those measures. For example species richness as a measure on its own takes no account of the number of individuals of each species present. It gives as much weight to those species which have very few individuals as to those which have many individuals [60]. Thus, for example, one springbok has as much influence on the measures of the richness of an area as 1000 eland. In our case we need extraordinary sample efforts to measure species richness which in effect may not reflect responses to management of the concern raised by managers. We thus argue that a focus on diversity and abundance of measures at several trophic levels will do well in evaluating 


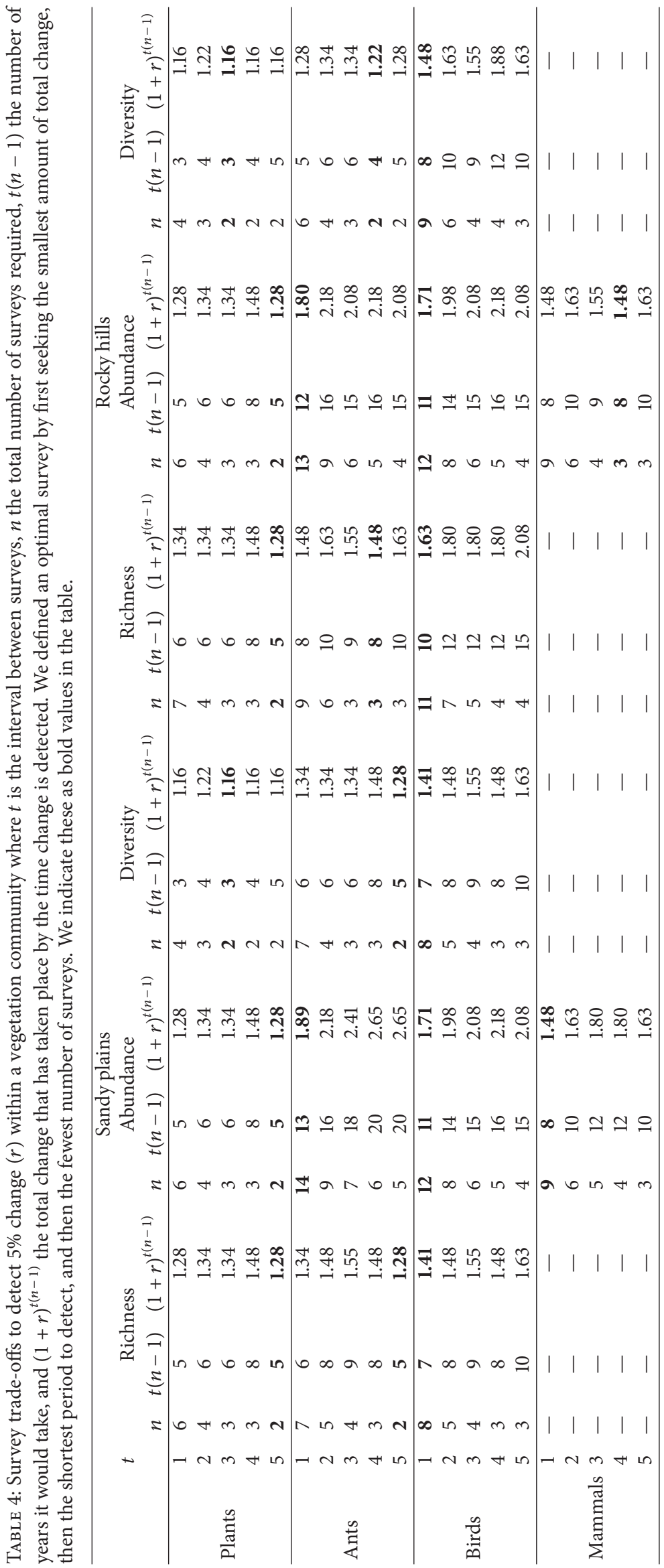


large effects of disturbance processes on ecosystems. Several studies on insects serve as examples and used measures of species diversity (e.g., [61]) and abundance (e.g., $[62,63])$ to evaluate effects of other types of disturbances (e.g., human development and chemically associated disturbances).

We also imply that structural measures such as richness, abundance, and diversity (e.g., [50]) may do better than functional measures such as productivity (e.g., [64]) in measuring ecosystem outcomes. We reason that functional outcomes will be restored if structural outcomes have been restored (e.g., [65]). However, structural outcomes are not associated with functional outcomes-the restoration of productivity for instance can be achieved with a range of structurally different vegetation types [64]. In short, similar function can be achieved with less structure.

The intense requirements to define and detect trends at landscape scales noted in our case study may carry some benefits. Most species' interactions happen at different scales both temporally and spatially (e.g., [66]). We recognize that landscapes are important for organisms as they support, comprise of factors, and allow opportunities for processes to play out that are necessary for the survival of organisms [67]. It is important to identify such factors as they drive and influence the conditions of persistence of different taxa. It is also important to realize that at times temporal fluctuations in parameters that we measured (e.g., annual fluctuations, [68]) can undermine detecting environmental change. A programme based on the approach we used in the resent study may thus benefit from collecting or collating baseline additional data such as weather data [69].

Of key significance though is the fact that most taxa with the exception of some large mammals (e.g., [26]) or seasonal migrating species like birds (e.g., [70]) respond to resources and factors influencing those at a local scale smaller (site or plot scale in our study) than what typical landscape scales may impose. The majority of insects, for instance, forage closer to their nest $[71,72]$ and only go further when the resources have been depleted. In addition, insects with low dispersal abilities are more impacted than mobile ones when disturbed at local scales [73]. Species thus typically respond to local conditions. In our case the site scale seems to be sensible given the species groups that we focused on as response variablesplants species, ants, and birds.

The advantages of understanding drivers as we seek in the present study are enhanced by using space-for-time approaches [74] simply because conservationists typically do not have the luxury of allowing ecosystems to evolve over some time or several generations. In our case several sites with different intensities of use by herbivores as indicated by dung densities serve as equivalent to a single site being allowed to experience a range of densities of herbivore use over time. This allows the potential unraveling of how herbivore use may influence biodiversity outcomes in a significantly shorter time. Space-for-time approaches work at landscape scales as well as site scales and have been successfully used to flag when management is failing to achieve specific objectives [29].

At the same time the heterogeneity paradigm adopted by modern conservation agencies makes use of defining thresholds of potential concern [10]. Such thresholds are best achieved within the heterogeneity paradigm when several places in a landscape show variability in how they change [8]. The scale at which species respond, ease of learning, and evaluation of management paradigms suggest that our evaluation of herbivory concerns in Mokala may be best achieved at a site scale where we have high confidence in defining measures precisely in terms of abundance and diversity.

We acknowledge that measures at site and plot scale can reflect landscape scale processes and may also carry emergent properties not detectable at site or plot scale alone [75]. For example, raptor communities varied in relation to habitat transformations, with lower abundance of individuals, richness, and diversity of species in more transformed landscapes. Small patches of natural vegetation and locations in which natural and cultivated lands were interspersed showed lower richness and diversity of raptors than large patches [76]. Fragmentation, an emergent property at a landscape scale, was the main cause of reductions in abundance of raptors.

\section{Conclusion}

Our results highlight that, even though unpacking conservation concerns into mechanisms gives strong direction for monitoring programmes, managers may need to evaluate feasibility of such programmes. In our case, measurement of species richness is highly unlikely to detect herbivore effects and requires survey efforts that impose unrealistic logistical challenges on managers. In general though, we have illustrated that focused monitoring designs can robustly evaluate conservation objectives appropriately. It is a key component of successfully implementing adaptive management approaches to systems-based conservation management.

\section{Authors' Contribution}

H. Bezuidenhout was the project leader, S. M. Ferreira was responsible for experimental and project design, and the whole team was responsible for field work, data analysis, and writing of the paper.

\section{Acknowledgments}

The study was financially supported by South African National Parks. The authors thank the managers of Mokala National Park for their logistical support and interest.

\section{References}

[1] G. E. Davis, "Design of a long-term ecological monitoring program for Channel Islands National Park, California," Natural Areas Journal, vol. 9, pp. 80-89, 1989.

[2] P. Vos, E. Meelis, and W. J. Ter Keurs, "A framework for the design of ecological monitoring programs as a tool for environmental and nature management," Environmental Monitoring and Assessment, vol. 61, no. 3, pp. 317-344, 2000.

[3] K. M. Havstad and J. E. Herrick, "Long-term ecological monitoring," Arid Land Research and Management, vol. 17, no. 4, pp. 389-400, 2003. 
[4] C. S. Holling, Adaptive Environmental Assessment and Management, John Wiley \& Sons, Chichester, UK, 1978.

[5] K. H. Rogers, "Operationalising ecology under a new paradigm," in Enhancing the Ecological Basis of Conservation: Heterogeneity, Ecosystem Function and Biodiversity, S. T. A. Pickett, R. S. Ostfeld, M. Schachak, and G. E. Likens, Eds., pp. 60-77, Chapman \& Hall, New York, NY, USA, 1997.

[6] M. A. Mcgeoch, M. Dopolo, P. Novellie et al., "A strategic framework for biodiversity monitoring in south African national parks," Koedoe, vol. 53, no. 2, article 991, 10 pages, 2011.

[7] D. B. Lindenmayer and G. E. Likens, "Adaptive monitoring: a new paradigm for long-term research and monitoring," Trends in Ecology and Evolution, vol. 24, no. 9, pp. 482-486, 2009.

[8] S. Ferreira, A. Deacon, H. Sithole, H. Bezuidenhout, M. Daemane, and M. Herbst, "From numbers to ecosystems and biodiversity: a mechanistic approach to monitoring," Koedoe, vol. 53, no. 2, article 998, 12 pages, 2011.

[9] T. Gerrodette, "A power analysis for detecting trends," Ecology, vol. 68, no. 5, pp. 1364-1372, 1987.

[10] H. Biggs, S. Ferreira, S. Freitag-Ronaldson, and R. Grant-Biggs, "Taking stock after a decade: does the "thresholds of potential concern" concept need a socio-ecological revamp?" Koedoe, vol. 53, no. 2, article 1002, 9 pages, 2011.

[11] W. D. Grossmann, "Socio-economic ecological models: criteria for evaluation of state-of-the-art models shown on four case studies," Ecological Modelling, vol. 76, pp. 21-36, 1994.

[12] R. E. Bowen and C. Riley, "Socio-economic indicators and integrated coastal management," Ocean and Coastal Management, vol. 46, no. 3-4, pp. 299-312, 2003.

[13] A. Gaylard and S. M. Ferreira, "Modification and maturation of SANPark's adaptive planning process-making critical linkages between conservation objectives and actions," Koedoe, vol. 53, no. 2, article 1005, 8 pages, 2011.

[14] A. J. Noss, "Challenges to nature conservation with community development in Central African forests," Oryx, vol. 31, no. 3, pp. 180-188, 1997.

[15] K. Brown, "Three challenges for a real people-centred conservation," Global Ecology and Biogeography, vol. 12, no. 2, pp. 89-92, 2003.

[16] K. Schmidt-Soltau, "Conservation-related resettlement in Central Africa: environmental and social risks," Development and Change, vol. 34, no. 3, pp. 525-551, 2003.

[17] T. A. Messmer, "The emergence of human-wildlife conflict management: turning challenges into opportunities," International Biodeterioration and Biodegradation, vol. 45, no. 3-4, pp. 97-102, 2000.

[18] S. M. Ferreira and D. Pienaar, "Degradation of the crocodile population in the Olifants River Gorge of Kruger National Park, South Africa," Aquatic Conservation: Marine and Freshwater Ecosystems, vol. 21, no. 2, pp. 155-164, 2011.

[19] H. H. Du Preez and G. J. Steyn, "A preliminary investigation of the concentration of selected metals in the tissues and organs of the tigerfish (Hydrocynus vittatus) from the Olifants River, Kruger National Park, South Africa," Water SA, vol. 18, pp. 131136, 1992.

[20] J. L. Nel, D. J. Roux, G. Maree et al., "Rivers in peril inside and outside protected areas: a systematic approach to conservation assessment of river ecosystems," Diversity and Distributions, vol. 13, no. 3, pp. 341-352, 2007.

[21] P. J. Ashton, "The demise of the Nile crocodile (Crocodylus niloticus) as a keystone species for aquatic ecosystem conservation in South Africa: the case of the Olifants River," Aquatic
Conservation: Marine and Freshwater Ecosystems, vol. 20, no. 5, pp. 489-493, 2010.

[22] H. Botha, W. van Hoven, and L. J. Guillette Jr., "The decline of the Nile crocodile population in Loskop Dam, Olifants River, South Africa," Water SA, vol. 37, no. 1, pp. 103-108, 2011.

[23] R. K. Plowright, S. H. Sokolow, M. E. Gorman, P. Daszak, and J. E. Foley, "Causal inference in disease ecology: investigating ecological drivers of disease emergence," Frontiers in Ecology and the Environment, vol. 6, no. 8, pp. 420-429, 2008.

[24] B. L. Johnson, "Introduction to the special feature: adaptive management - scientifically sound, socially challenged?” Ecology and Society, vol. 3, no. 1, article 10, 1999.

[25] G. F. Wilhere, "Adaptive management in habitat conservation plans," Conservation Biology, vol. 16, no. 1, pp. 20-29, 2002.

[26] M. J. Trimble and R. J.van Aarde, "Fences are more than an issue of aesthetics," BioScience, vol. 60, no. 7, p. 486, 2010.

[27] R. J. Van Aarde, A.-M. Smit, and A. S. Claassens, "Soil characteristics of rehabilitating and unmined coastal dunes at Richards Bay, KwaZulu-Natal, South Africa," Restoration Ecology, vol. 6, no. 1, pp. 102-110, 1998.

[28] T. D. Wassenaar, R. J. Van Aarde, S. L. Pimm, and S. M. Ferreira, "Community convergence in disturbed subtropical dune forests," Ecology, vol. 86, no. 3, pp. 655-666, 2005.

[29] T. D. Wassenaar, S. M. Ferreira, and R. J. Van Aarde, "Flagging aberrant sites and assemblages in restoration projects," Restoration Ecology, vol. 15, no. 1, pp. 68-76, 2007.

[30] F. Pulido, E. García, J. J. Obrador, and G. Moreno, "Multiple pathways for tree regeneration in anthropogenic savannas: incorporating biotic and abiotic drivers into management schemes," Journal of Applied Ecology, vol. 47, no. 6, pp. 12721281, 2010.

[31] E. C. Weatherhead, G. C. Reinsel, G. C. Tiao et al., "Factors affecting the detection of trends: statistical considerations and applications to environmental data," Journal of Geophysical Research D, vol. 103, no. 14, pp. 17149-17161, 1998.

[32] R. F. W. Barnes, "The problem of precision and trend detection posed by small elephant populations in West Africa," African Journal of Ecology, vol. 40, no. 2, pp. 179-185, 2002.

[33] Agricultural Research Council, "ARC-ISCW AgroClimatology Daily Data Report (DDR Format, Limited Quality Control)," in ARC-ISCW Climate Information System, ARC-Institute for Soil, Climate and Water, Pretoria, South Africa, 2011.

[34] L. Mucina and M. C. Rutherford, The Vegetation of South Africa, Lesotho and Swaziland, Strelitzia 19, South African National Biodiversity Institute, Pretoria, South Africa, 2006.

[35] H. Bezuidenhout and P. Bradshaw, "Vegetation landscapes of Mokala National Park (Northern Cape)," Unpublished Internal Report for SANParks, Scientific Services, Kimberley, Australia, 2013.

[36] A. J. Plumptre, "Monitoring mammal populations with line transect techniques in African forests," Journal of Applied Ecology, vol. 37, no. 2, pp. 356-368, 2000.

[37] A. V. Suarez, D. T. Bolger, and T. J. Case, "Effects of fragmentation and invasion on native ant communities in coastal southern California," Ecology, vol. 79, no. 6, pp. 2041-2056, 1998.

[38] A. N. Andersen, B. D. Hoffmann, W. J. Müller, and A. D. Griffiths, "Using ants as bioindicators in land management: simplifying assessment of ant community responses," Journal of Applied Ecology, vol. 39, no. 1, pp. 8-17, 2002.

[39] A. N. Andersen and J. D. Majer, "Ants show the way Down Under: invertebrates as bio-indicators in land management," 
Frontiers in Ecology and the Environment, vol. 2, pp. 291-298, 2004.

[40] E. C. Underwood and B. L. Fisher, "The role of ants in conservation monitoring: if, when, and how," Biological Conservation, vol. 132, no. 2, pp. 166-182, 2006.

[41] D. Pomeroy, Counting Birds: A Guide to Assessing Numbers, Biomass and Diversity of Afrotropical Birds, vol. 6 of AWF Technical Handbook Series, African Wildlife Foundation, Nairobi, Kenya, 1992.

[42] R. A. Ryder, "Songbirds," in Inventory and Monitoring of Wildlife Habitat, A. Y. Cooperrider, R. J. Boyd, and H. R. Stuart, Eds., pp. 1-858, U.S. Department of the Interior-Bureau of Land Management, Service Center, Denver, Colo, USA, 1986.

[43] D. Mueller-Dombois and H. Ellenberg, Aims and Methods of Vegetation Ecology, John Wiley \& Sons, New York, NY, USA, 1974.

[44] G. Germishuizen and N. L. Meyer, Plants of Southern Africa: An Annotated Checklist, Strelitzia 14, National Botanical Institute, Pretoria, South Africa, 2003.

[45] J. J. Barkman, H. Doing, and S. Segal, "Bemerkungen und Vorschläge zur quantitativen Vegetationsanalyse [Critical remarks and suggestions for the quantitative analysis of vegetation]," Acta Botanica Neerlandica, vol. 13, pp. 394-419, 1964.

[46] H. D. Foth, L. V. Wilthee, H. S. Jacobs, and S. J. Thien, Laboratory Manual for Introductory Soil Science, WM.C. Brown Company, Dubuque, Iowa, USA, 4th edition, 1978.

[47] C. T. Parr and S. L. Chown, "Inventory and bioindicator sampling: testing pitfall and winkler methods with ants in a South African savanna," Journal of Insect Conservation, vol. 5, no. 1, pp. 27-36, 2001.

[48] J. Adis, "Problems of interpreting arthropod sampling with pitfall traps," Zoologischer Anzeiger, vol. 202, pp. 117-184, 1979.

[49] B. Bolton, Identification Guide to the Ant Genera of the World, Harvard University Press, London, UK, 1997.

[50] R. Gorelick, "Combining richness and abundance into a single diversity index using matrix analogues of Shannon's and Simpson's indices," Ecography, vol. 29, no. 4, pp. 525-530, 2006.

[51] C. Krebs, Ecological Methodology, HarperCollins, New York, NY, USA, 1989.

[52] D. B. Lindenmayer, "Future directions for biodiversity conservation in managed forests: indicator species, impact studies and monitoring programs," Forest Ecology and Management, vol. 115, no. 2-3, pp. 277-287, 1999.

[53] J. Niemelä, "Biodiversity monitoring for decision-making," Annales Zoologici Fennici, vol. 37, no. 4, pp. 307-317, 2000.

[54] A. N. Andersen, A. Fisher, B. D. Hoffmann, J. L. Read, and R. Richards, "Use of terrestrial invertebrates for biodiversity monitoring in Australian rangelands, with particular reference to ants," Austral Ecology, vol. 29, no. 1, pp. 87-92, 2004.

[55] I. Watson and P. Novelly, "Making the biodiversity monitoring system sustainable: design issues for large-scale monitoring systems," Austral Ecology, vol. 29, no. 1, pp. 16-30, 2004.

[56] S. K. Thompson, Sampling, John Wiley \& Sons, New York, NY, USA, 1992.

[57] M. Henry, J. F. Cosson, and J. M. Pons, "Modelling multi-scale spatial variation in species richness from abundance data in a complex neotropical bat assemblage," Ecological Modelling, vol. 221, no. 17, pp. 2018-2027, 2010.

[58] A. E. Reside, J. J. Vanderwal, A. S. Kutt, and G. C. Perkins, "Weather, not climate, defines distributions of vagile bird species," PLoS ONE, vol. 5, no. 10, article e13569, 2010.
[59] J. J. Kritzinger and R. J. Van Aarde, "The bird communities of rehabilitating coastal dunes at Richards Bay, KwaZulu-Natal," South African Journal of Science, vol. 94, no. 2, pp. 71-78, 1998.

[60] O. L. Petchey and K. J. Gaston, "Functional diversity: back to basics and looking forward," Ecology Letters, vol. 9, no. 6, pp. 741-758, 2006.

[61] A. J. Davis, J. D. Holloway, H. Huijbregts, J. Krikken, A. H. KirkSpriggs, and S. L. Sutton, "Dung beetles as indicators of change in the forests of northern Borneo," Journal of Applied Ecology, vol. 38, no. 3, pp. 593-616, 2001.

[62] R. B. Blair and A. E. Launer, "Butterfly diversity and human land use: species assemblages along an urban gradient," Biological Conservation, vol. 80, no. 1, pp. 113-125, 1997.

[63] B. D. Hoffmann, A. D. Griffiths, and A. N. Andersen, "Responses of ant communities to dry sulfur deposition from mining emissions in semi-arid tropical Australia, with implications for the use of functional groups," Austral Ecology, vol. 25, no. 6, pp. 653-663, 2000.

[64] W. Li and M. Stevens, "High community dissimilarity at low productivity causes the productivity-richness relation to vary with observational scale," Community Ecology, vol. 11, no. 1, pp. 27-34, 2010.

[65] P. M. Holmes and D. M. Richardson, "Protocols for restoration based on recruitment dynamics, community structure, and ecosystem function: perspectives from South African fynbos," Restoration Ecology, vol. 7, no. 3, pp. 215-230, 1999.

[66] C. Polce, W. E. Kunin, J. C. Biesmeijer, J. Dauber, and O. L. Phillips, "Alien and native plants show contrasting responses to climate and land use in Europe," Global Ecology and Biogeography, vol. 20, no. 3, pp. 367-379, 2011.

[67] J. N. M. Smith and J. J. Hellmann, "Population persistence in fragmented landscapes," Trends in Ecology and Evolution, vol. 17, no. 9, pp. 397-399, 2002.

[68] W. A. Scott and R. Anderson, “Temporal and spatial variation in carabid assemblages from the United Kingdom Environmental Change Network," Biological Conservation, vol. 110, no. 2, pp. 197-210, 2003.

[69] L. M. Crump, "Climate and environment," in Measuring and Monitoring Biological Diversity. Standard Methods for Amphibians, W. R. Heyer, M. A. Donnelly, R. W. McDiarmid, L. Hayek, and M. S. Foster, Eds., pp. 42-46, Smithsonian Institution Press, Washington, DC, USA, 1994.

[70] O. Gilg and N. G. Yoccoz, "Explaining bird migration," in Science, vol. 327, article 959, 2010.

[71] A. Gathmann and T. Tscharntke, "Foraging ranges of solitary bees," Journal of Animal Ecology, vol. 71, no. 5, pp. 757-764, 2002.

[72] E. Öckinger and H. G. Smith, "Semi-natural grasslands as population sources for pollinating insects in agricultural landscapes," Journal of Applied Ecology, vol. 44, no. 1, pp. 50-59, 2007.

[73] D. Maes and H. Van Dyck, "Butterfly diversity loss in Flanders (north Belgium): Europe's worst case scenario?” Biological Conservation, vol. 99, no. 3, pp. 263-276, 2001.

[74] P. Legendre, M. De Cáceres, and D. Borcard, "Community surveys through space and time: testing the space-time interaction in the absence of replication," Ecology, vol. 91, no. 1, pp. 262-272, 2010.

[75] B. K. Van Wesenbeeck, J. Van De Koppel, P. M. J. Herman et al., "Potential for sudden shifts in transient systems: distinguishing between local and landscape-scale processes," Ecosystems, vol. 11, no. 7, pp. 1133-1141, 2008. 
[76] M. Carrete, J. A. Sánchez-Zapata, J. R. Benítez, M. Lobón, and J. A. Donázar, "Large scale risk-assessment of wind-farms on population viability of a globally endangered long-lived raptor," Biological Conservation, vol. 142, no. 12, pp. 2954-2961, 2009. 

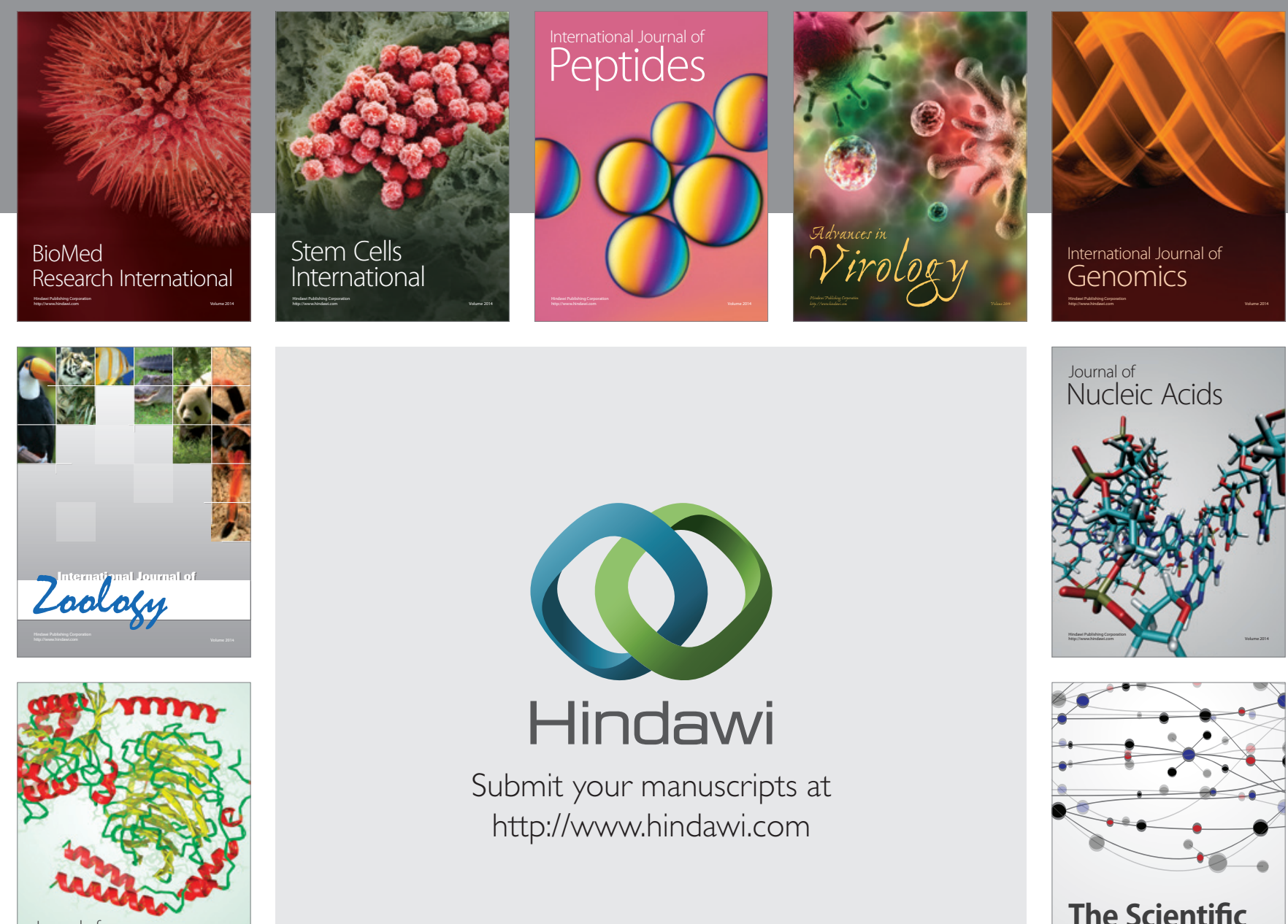

Submit your manuscripts at

http://www.hindawi.com

Journal of
Signal Transduction
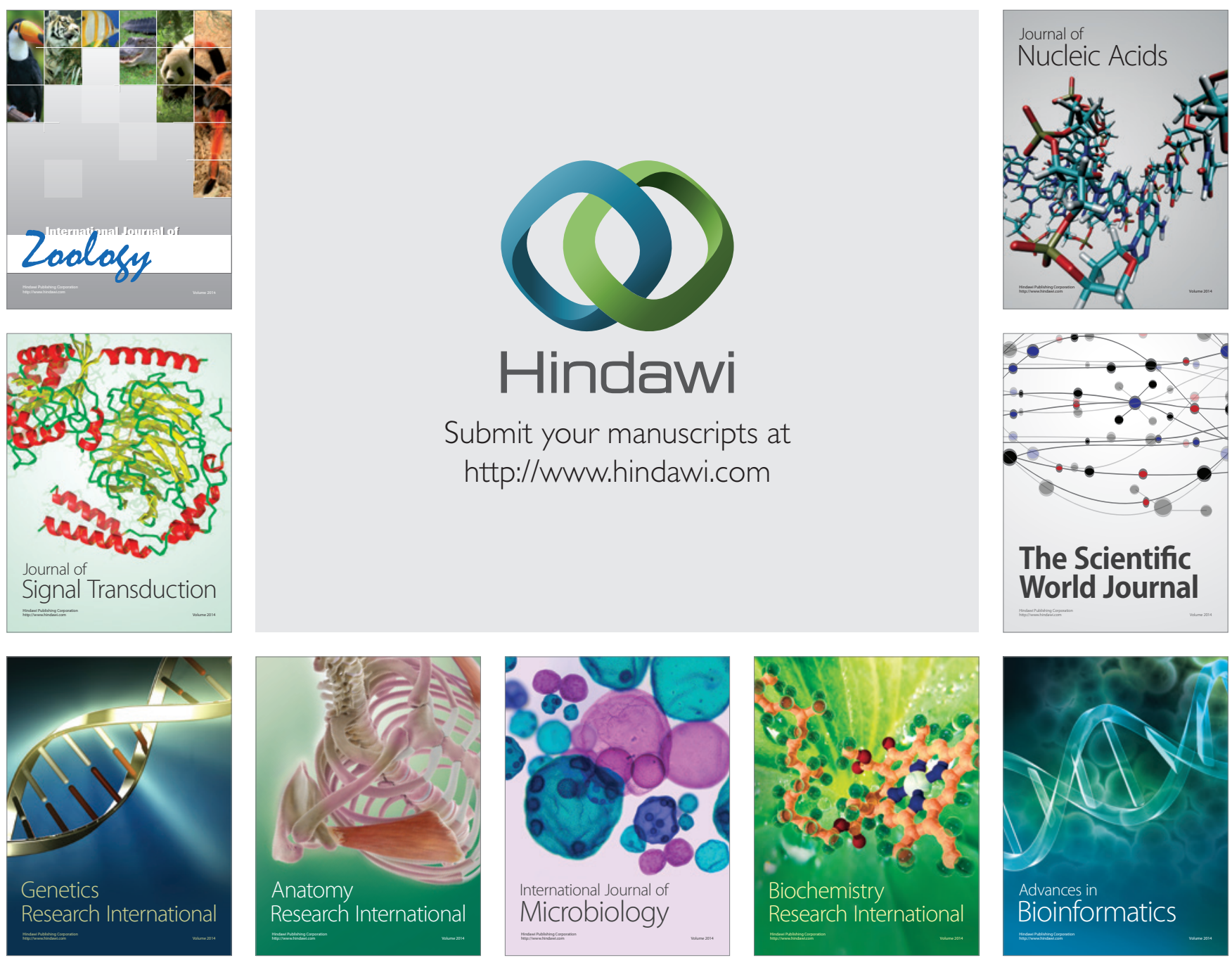

The Scientific World Journal
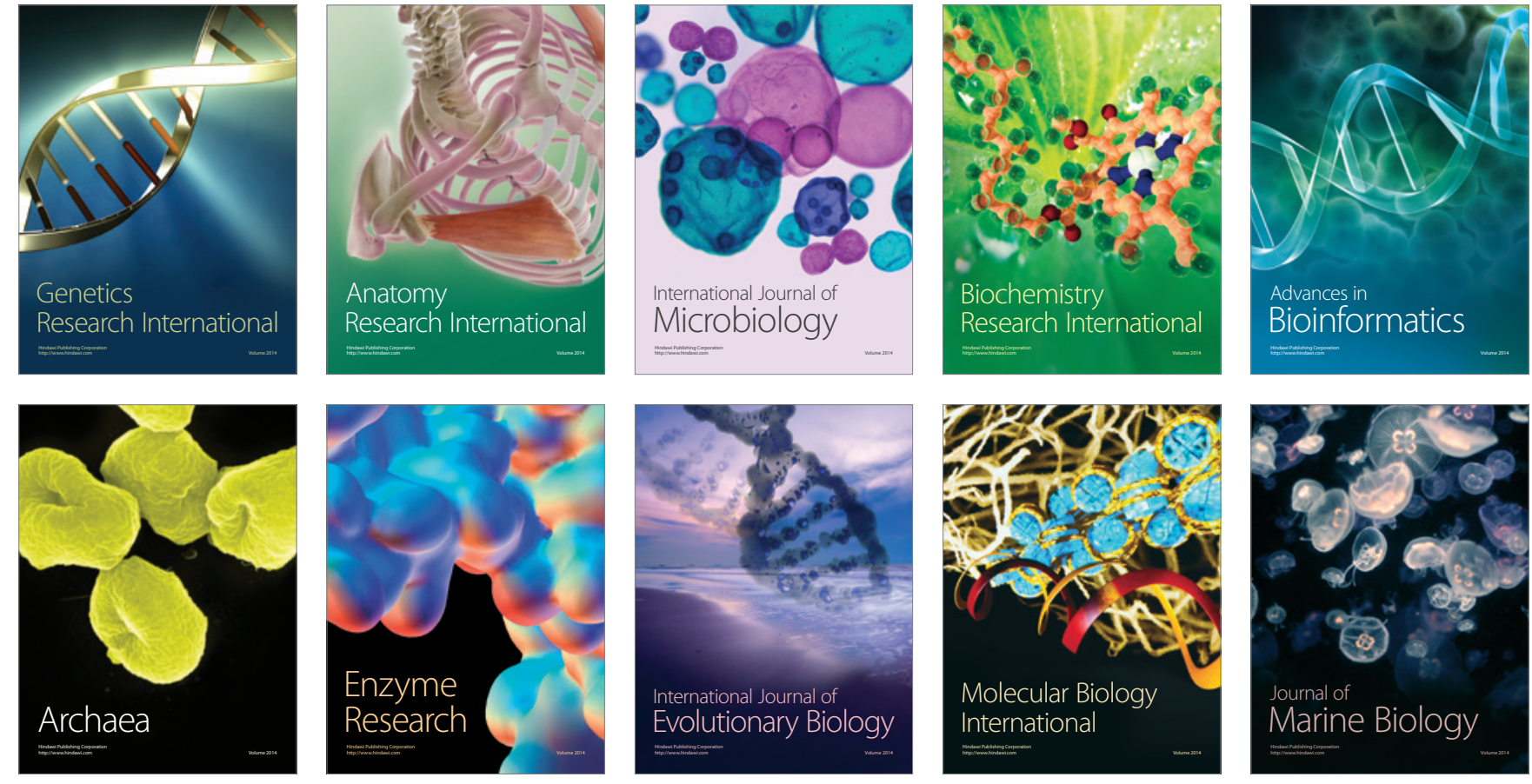